\title{
ANALISIS LENDUTAN PERKERASAN KAKU PADA PEMBEBANAN SUDUT DENGAN METODE ELEMEN HINGGA
}

\author{
Farid Yasir ${ }^{1}$, Niken Silmi Surjandari ${ }^{2}$, Yusep Muslih Purwana ${ }^{3}$ \\ 1) Mahasiswa Magister Teknik, Jurusan Teknik Sipil, Universitas Sebelas Maret Surakarta, \\ faridyasir@gmail.com \\ ${ }^{2)}$ Dosen Magister Teknik, Jurusan Teknik Sipil, Universitas Sebelas Maret Surakarta, \\ nikensilmisurjandari@gmail.com \\ ${ }^{3)}$ Dosen Magister Teknik, Jurusan Teknik Sipil, Universitas Sebelas Maret Surakarta, \\ ymuslih@yahoo.com
}

\begin{abstract}
ABSTRAK
Perkerasan kaku adalah salah satu jenis perkerasan untuk menangani permasalahan akibat daya dukung tanah yang rendah. Tebal perkerasan merupakan salah satu yang diperhitungkan agar tidak terjadi lendutan yang melebihi lendutan yang diijinkan pada tanah dasarnya. Penggunaan koperan pada ujung pelat perkerasan kaku adalah alternatif solusi untuk mengatasi permasalahan lendutan. Penelitian ini bertujuan untuk mengetahui lendutan pada perkerasan kaku akibat beban pada posisi sudut dengan variasi ketebalan dan penambahan koperan. Besarnya lendutan akibat pembebanan sudut dianalisis dengan Metode Elemen Hingga. Model pelat berukuran 6x3 $m$ dengan variasi tebal $15 \mathrm{~cm}, 20 \mathrm{~cm}, 25 \mathrm{~cm}, 30 \mathrm{~cm}$ dan $35 \mathrm{~cm}$, nilai CBR 10\%, mutu beton yang digunakan adalah K350, posisi pembebanan sudut dengan beban 8 ton dan koperan lebar $25 \mathrm{~cm}$ tinggi $50 \mathrm{~cm}$. Penggunaan koperan dapat mereduksi lendutan hingga 42,36\% pada tebal $15 \mathrm{~cm}$ dan semakin turun dengan bertambahnya tebal pelat hingga sebesar 13,13\% pada tebal $35 \mathrm{~cm}$, sehingga dapat diperoleh tebal perkerasan yang lebih kecil, sebagaimana dalam hasil analisis pelat tebal $35 \mathrm{~cm}$ tanpa koperan diperoleh lendutan maksimum sebesar 10,659 mm atau lebih besar lendutannya dari pelat tebal $25 \mathrm{~cm}$ menggunakan koperan dengan lendutan maksimum sebesar 10,413 mm.
\end{abstract}

Kata kunci: perkerasan kaku, koperan, lendutan, metode elemen hingga.

\section{PENDAHULUAN}

Perkerasan kaku merupakan salah satu jenis perkerasan yang umumnya digunakan untuk mengatasi permasalahan akibat daya dukung tanah yang rendah. Penentuan jenis perkerasan ditentukan berdasarkan jenis beban, keadaan tanah dan pertimbangan ekonomi lainnya (Firdaus, 2010). Pada perkerasan kaku, seluruh beban roda dipikul oleh slab beton.

Penggunaan koperan pada ujung pelat perkerasan kaku sudah dilakukan pada penelitian Puri, dkk (2013) dalam penelitian Sistem Pelat Terpaku (Nailed-slab System) sebagai salah satu alternatif solusi untuk mengatasi permasalahan konstruksi jalan yang melalui tanah lunak, yang terdiri atas pelat beton bertulang dan tiang-tiang mikro yang dipasang di bawah pelat tersebut dengan hubungan pelat dan tiang dibuat monolit. Pada bagian kedua ujung pelat dapat pula diperkuat dengan pelat koperan (vertical concrete wall barrier) yang fungsi utamanya untuk mereduksi lendutan akibat beban di pinggir perkerasan. Penggunaan koperan juga dipakai pada desain perkerasan kaku pada Jalan Surakarta - Gemolong - Geyer Batas Grobogan.

Lendutan yang terjadi pada perkerasan akan mempengaruhi stabilitas struktur apabila melebihi lendutan yang diijinkan pada tanah dasarnya.

Metode Elemen Hingga bisa menjadi alternatif dalam analisis dan desain perkerasan kaku (Islam, 2014). Metode Elemen Hingga disarankan sebagai metode alternatif untuk menghitung tekanan perkerasan kaku (Maske., dkk, 2013). 


\section{METODE PENELITIAN}

Metode penelitian yang digunakan dalam penelitian ini memakai metode deskriptif kuantitatif dan metode eksperimental untuk membuat pemodelan struktur perkerasan kaku yang dianalisis lendutannya dengan metode elemen hingga program SAP-2000 v.14. Model perkerasan kaku berupa pelat berukuran $6 \times 3 \mathrm{~m}$ dengan variasi tebal $15 \mathrm{~cm}, 20 \mathrm{~cm}, 25 \mathrm{~cm}, 30 \mathrm{~cm}$ dan $35 \mathrm{~cm}$, dengan nilai CBR $10 \%$, mutu beton yang digunakan adalah $\mathrm{K} 350$, beban 8 ton pada posisi pembebanan sudut (corner loading), tanpa koperan dan dengan menggunakan koperan. Koperan yang digunakan lebar $25 \mathrm{~cm}$ dengan tinggi $50 \mathrm{~cm}$. Tahapan penelitian ini yaitu dengan melakukan analisis dengan membuat model pada program SAP-2000 v.14. dengan dilakukan variasi tebal pelat pada kondisi tanpa koperan dan dengan koperan. Output yang dihasilkan dari analisis dengan MEH berupa besaran lendutan pada setiap varisasi penelitian.

\section{ANALISIS DAN PEMBAHASAN}

\section{Modulus reaksi tanah dasar (k) sebagai tumpuan pegas}

Tanah dasar yang dipakai sebagai tumpuan lapisan perkerasan kaku diasumsikan sebagai tumpuan pegas dengan nilai kekakuan pegas dengan pemodelan sebagai berikut:

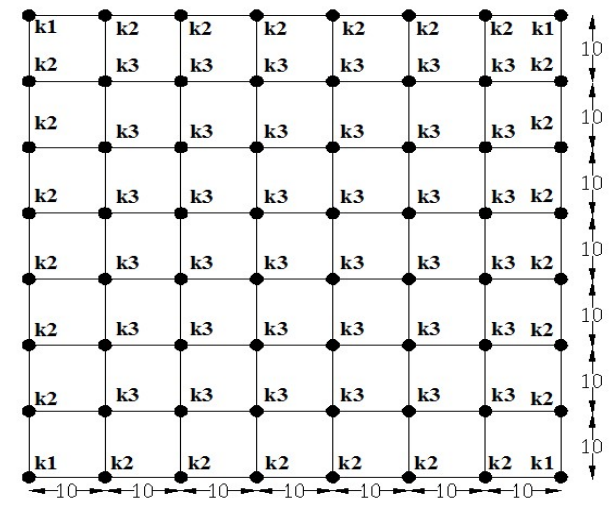

Gambar 1. Model tumpuan pegas pada perkerasan kaku

Modulus reaksi tanah dasar dapat diperoleh dari nilai CBR dengan menggunakan hubungan nilai CBR dengan modulus reaksi tanah dasar $(\mathrm{k})$ seperti gambar 2.

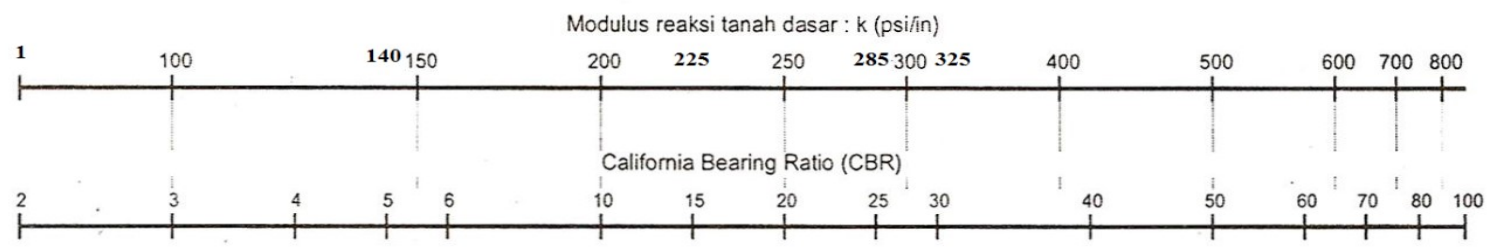

(Oglesby dan Hicks, 1996 dalam Suryawan, 2009)

Gambar 2. Hubungan antara $k$ dan CBR

Pada penelitian ini CBR tanah dasar yang digunakan adalah CBR 10\%. Berdasarkan nilai CBR tersebut dapat diperoleh besarnya modulus reaksi tanah dasar (k) sebesar 200 psi/in atau setara dengan $5,538 \mathrm{~kg} / \mathrm{cm}^{3}$.

Berdasarkan data di atas, dengan jarak antar tumpuan arah memanjang sebesar $10 \mathrm{~cm}$ dan jarak antar tumpuan pegas arah melebar sebesar $10 \mathrm{~cm}$, nilai-nilai kekakuan pegas $\mathrm{k} 1, \mathrm{k} 2$ dan $\mathrm{k} 3$ dihitung sebagai berikut: 
- $\quad \mathrm{k} 1=5,00 \times 5,00 \times 5,538=138,457 \mathrm{~kg} / \mathrm{cm}^{\prime}$

- $\quad \mathrm{k} 2=5,00 \times 10,00 \times 5,538=276,915 \mathrm{~kg} / \mathrm{cm}^{\prime}$

- $\quad \mathrm{k} 3=10,00 \times 10,00 \times 5,538=553,830 \mathrm{~kg} / \mathrm{cm}^{\prime}$

\section{Pembebanan beban gandar rencana}

Muatan Sumbu Terberat (MST) berdasarkan kelas jalan adalah sebesar 8 ton, 10 ton dan $>10$ ton (Anonim, 1997), yang dalam analisis struktur perkerasan ditentukan sebagai beban statis.

Desain beban gandar dan ekivalensi luas bidang kontak untuk MST $=8$ ton seperti pada gambar 3 dan 4 .

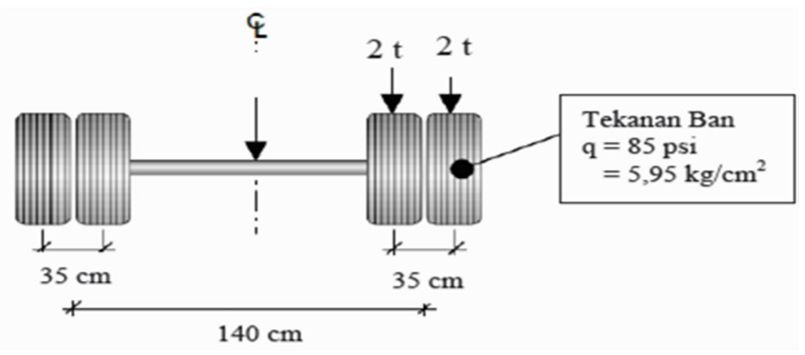

Gambar 3. Design Axle Load Standard Axle Load
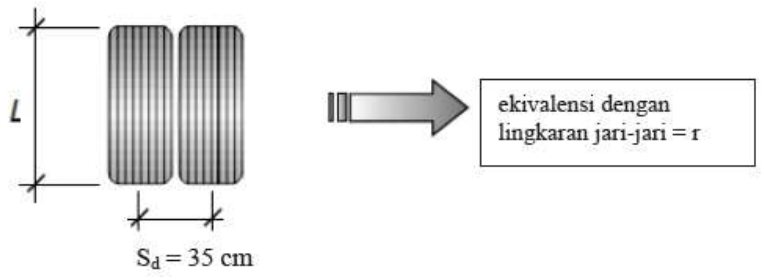

Gambar 4. Ekivalensi luas bidang kontak lingkaran

Area kontak roda disederhanakan berbentuk lingkaran dengan jari-jari r adalah:

$$
\begin{aligned}
& L=\sqrt{\frac{P d}{0,5227 \cdot q}}=\sqrt{\frac{2000}{0,5227.5,95}}=25,36 \mathrm{~cm} \\
& \pi r^{2}=\left(2 \times 0,5227 \times \mathrm{L}^{2}\right)+((\mathrm{Sd}-0,6) \times \mathrm{L}) \\
& \pi r^{2}=\left(0,4454 \times 25,36^{2}\right)+((35-0,6) \times 25,36) \\
& \pi r^{2}=1158,83 \\
& r=\sqrt{\frac{1158,83}{\pi}}=19,21 \approx 20 \mathrm{~cm}
\end{aligned}
$$

Sehingga area kontak beban roda seperti gambar 5 .

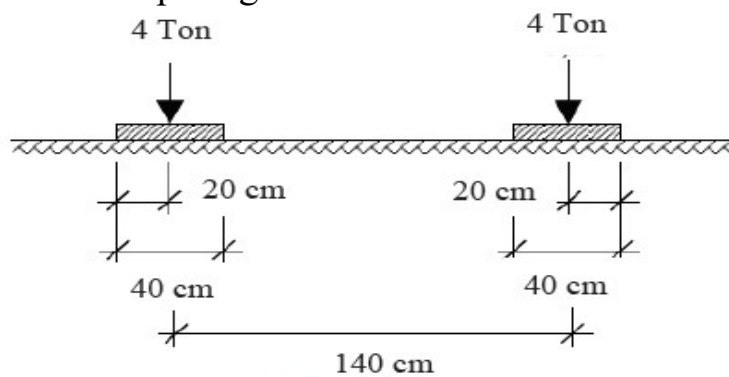

Gambar 5. Area kontak beban roda 


\section{Posisi Pembebanan}

Pembebanan yang terjadi pada pelat beton akibat pembebanan roda (lalu lintas) adalah pembebanan ujung, pembebanan tengah dan pembebanan pinggir (Suryawan, 2009). Pada penelitian ini digunakan pembebanan ujung/sudut (corner loading).

\section{Koperan}

Koperan sebagai struktur perkuatan pada tepi pelat pada penelitian ini menggunakan dimensi lebar $(d)=25 \mathrm{~cm}$ dan tinggi $(\mathrm{h})=50 \mathrm{~cm}$.

\section{Pemodelan Struktur}

Pemodelan struktur yang dianalisis seperti gambar 6.

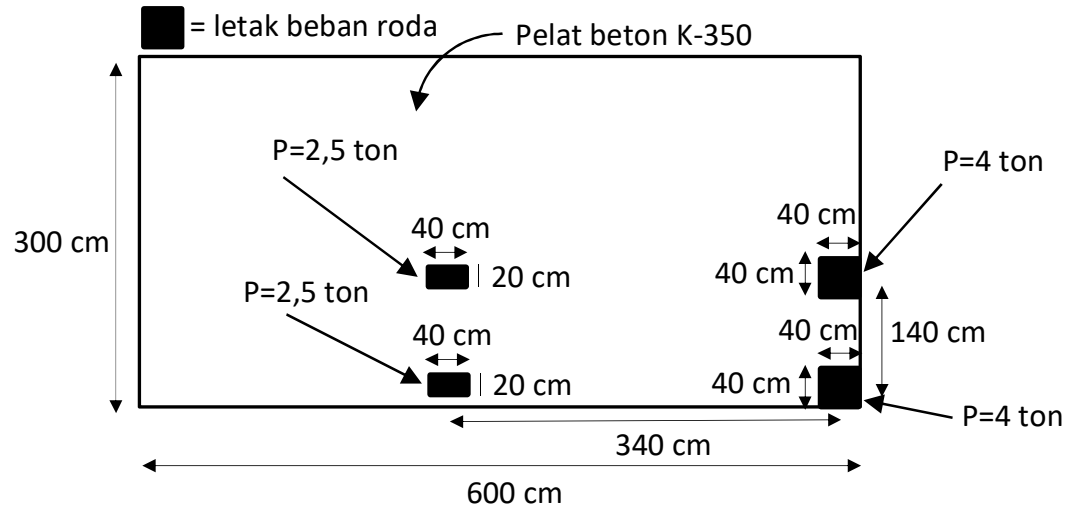

a. Denah pelat dan pembebanan

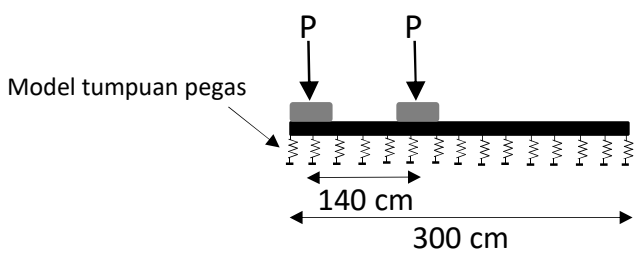

b. Penampang melintang pelat tanpa koperan

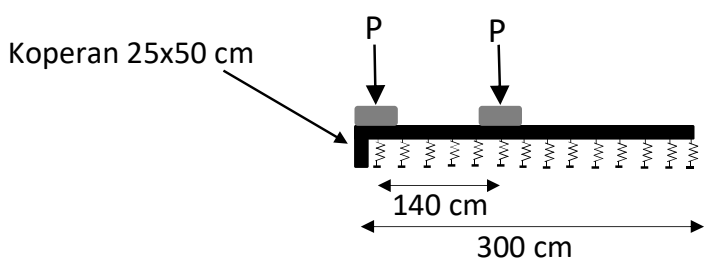

c. Penampang melintang pelat dengan koperan

Gambar 6. Pemodelan struktur perkerasan kaku

\section{Lendutan pelat pada pembebanan sudut}

Hasil analisis ditampilkan dalam grafik hasil lendutan pelat pada potongan melintang akibat pembebanan sudut beban 8 ton dengan variasi tebal pelat $15 \mathrm{~cm}, 20 \mathrm{~cm}, 25 \mathrm{~cm}, 30 \mathrm{~cm}$ dan $35 \mathrm{~cm}$ pada nilai CBR 10\% dan mutu beton K350 dengan kondisi tanpa koperan dan menggunakan koperan.

Nilai lendutan dari hasil analisis disajikan pada gambar 7. 


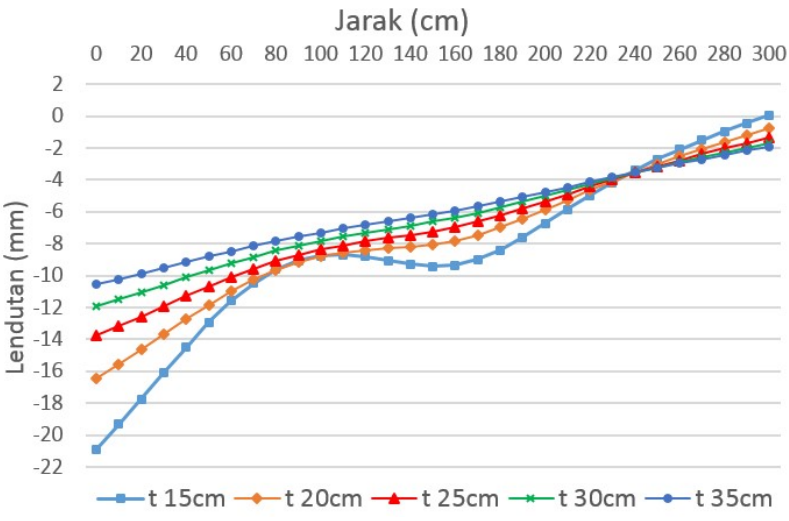

a. Lendutan pada pelat tanpa koperan

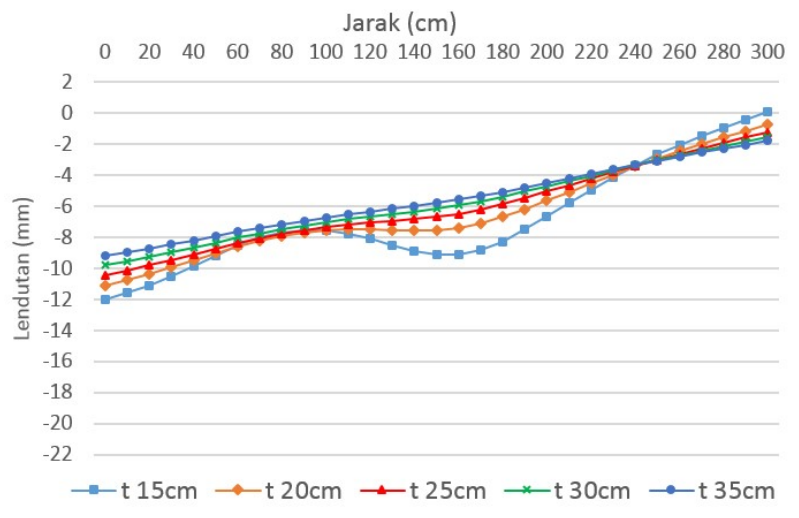

b. Lendutan pada pelat dengan koperan

Gambar 7. Lendutan pelat pada pembebanan sudut

Dari hasil lendutan maksimum, pada kondisi pelat tanpa koperan lendutan maksimum terbesar pada tebal $15 \mathrm{~cm}$, kemudian diikuti pada tebal $20 \mathrm{~cm}, 25 \mathrm{~cm}, 30 \mathrm{~cm}$ dan $35 \mathrm{~cm}$.

Pada kondisi pelat dengan koperan lendutan maksimum terbesar pada tebal $15 \mathrm{~cm}$, kemudian diikuti pada tebal $20 \mathrm{~cm}, 25 \mathrm{~cm}, 30 \mathrm{~cm}$ dan $35 \mathrm{~cm}$.

Hasil lendutan antara pelat tanpa koperan dan pelat dengan koperan pada variasi tebal pelat seperti gambar berikut:

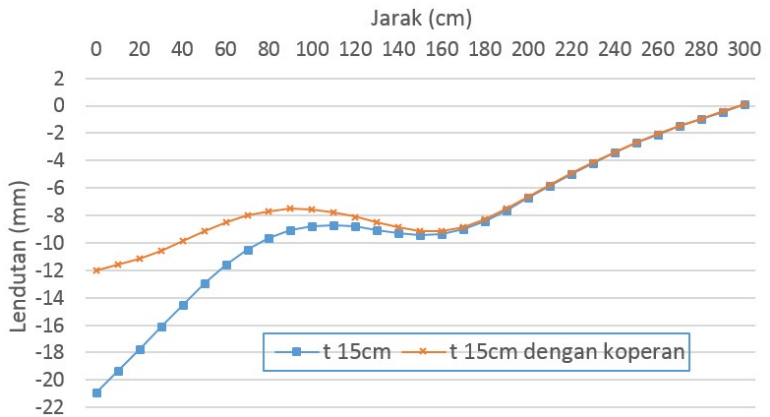

a. Lendutan pada pelat tebal $15 \mathrm{~cm}$

$\begin{array}{llllllllllllllll}0 & 20 & 40 & 60 & 80 & 100 & 120 & 140 & 160 & 180 & 200 & 220 & 240 & 260 & 280 & 300\end{array}$

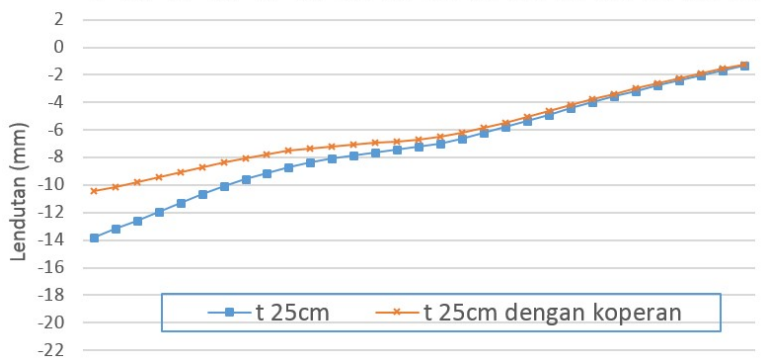

c. Lendutan pada pelat tebal $25 \mathrm{~cm}$
Jarak $(\mathrm{cm})$

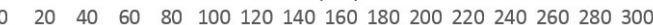

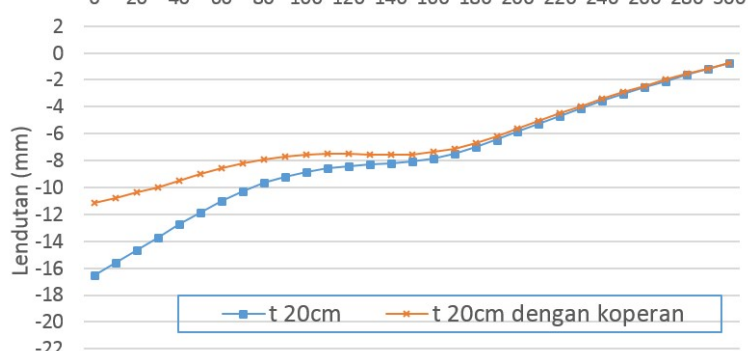

b. Lendutan pada pelat tebal $20 \mathrm{~cm}$

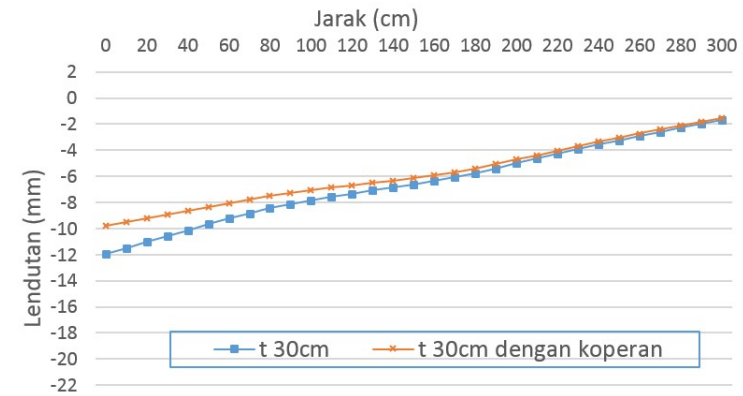

d. Lendutan pada pelat tebal $30 \mathrm{~cm}$ 


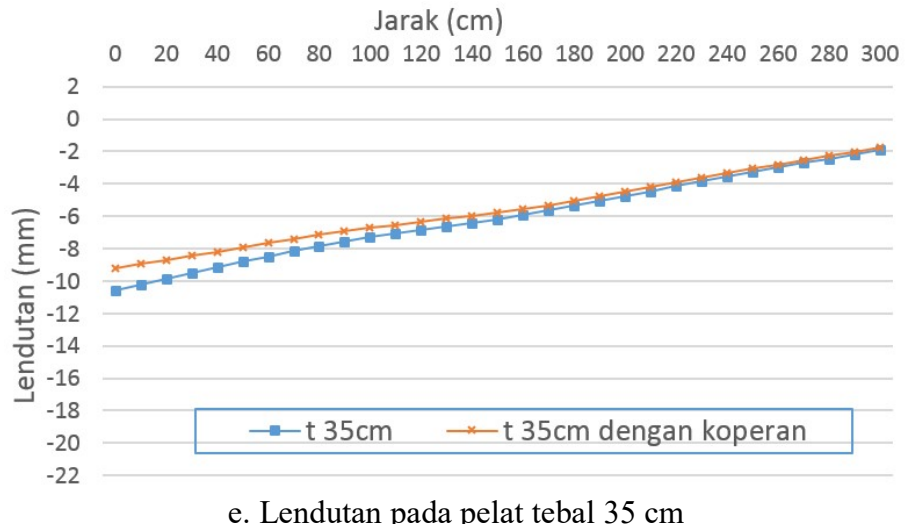

Gambar 8. Lendutan pelat dengan variasi tebal pada kondisi tanpa koperan dan menggunakan koperan

Tabel 1. Perbandingan lendutan posisi pembebanan sudut (CBR 10\%, K350, beban 8 ton)

\begin{tabular}{c|c|c|c}
\hline \multirow{2}{*}{ Tebal (cm) } & \multicolumn{2}{|c|}{ Lendutan maksimum (mm) } & \multirow{2}{*}{ Selisih \% } \\
\cline { 2 - 3 } & Pelat Tanpa Koperan & Pelat Dengan Koperan & \\
\hline 15 & -20.876 & -12.032 & 42.36 \\
\hline 20 & -16.491 & -11.110 & 32.63 \\
\hline 25 & -13.782 & -10.413 & 24.45 \\
\hline 30 & -11.928 & -9.780 & 18.01 \\
\hline 35 & -10.569 & -9.182 & 13.13 \\
\hline
\end{tabular}

Berdasarkan tabel 1 dapat diuraikan sebagai berikut:

a. Posisi pembebanan sudut dengan kondisi pelat tanpa koperan menghasilkan lendutan maksimum terbesar pada pelat dengan tebal $15 \mathrm{~cm}$ sebesar $20,876 \mathrm{~mm}$ dan lendutan maksimum terkecil pada pelat dengan tebal $35 \mathrm{~cm}$ sebesar $10,659 \mathrm{~mm}$.

b. Posisi pembebanan sudut dengan kondisi pelat menggunakan koperan menghasilkan lendutan maksimum terbesar pada pelat dengan tebal $15 \mathrm{~cm}$ sebesar $12,032 \mathrm{~mm}$ dan lendutan maksimum terkecil pada pelat dengan tebal $35 \mathrm{~cm}$ sebesar $9,182 \mathrm{~mm}$.

c. Lendutan maksimum pada pelat tebal $15 \mathrm{~cm}$ tanpa koperan sebesar $20,876 \mathrm{~mm}$ dan pelat dengan koperan sebesar 12,032 $\mathrm{mm}$ atau mengalami penurunan sebesar 42,36\%

d. Lendutan maksimum pada pelat tebal $20 \mathrm{~cm}$ tanpa koperan sebesar $16,491 \mathrm{~mm}$ dan pelat dengan koperan sebesar 11,110mm atau mengalami penurunan sebesar 32,63\%

e. Lendutan maksimum pada pelat tebal $25 \mathrm{~cm}$ tanpa koperan sebesar $13.782 \mathrm{~mm}$ dan pelat dengan koperan sebesar 10,413mm atau mengalami penurunan sebesar 24,45\%

f. Lendutan maksimum pada pelat tebal $30 \mathrm{~cm}$ tanpa koperan sebesar $11,928 \mathrm{~mm}$ dan pelat dengan koperan sebesar 9,780 $\mathrm{mm}$ atau mengalami penurunan sebesar $18,01 \%$

g. Lendutan maksimum pada pelat tebal $35 \mathrm{~cm}$ tanpa koperan sebesar $10,569 \mathrm{~mm}$ dan pelat dengan koperan sebesar 9,182 $\mathrm{mm}$ atau mengalami penurunan sebesar 13,13\%

h. Prosentase penurunan antara pelat tanpa koperan dan pelat dengan koperan terbesar terjadi pada pelat tebal $15 \mathrm{~cm}$ yaitu sebesar $42,36 \%$ dan semakin turun dengan bertambahnya tebal pelat sampai penurunan terkecil terjadi pada pelat tebal $35 \mathrm{~cm}$ yaitu sebesar $13,13 \%$. 


\section{SIMPULAN}

Berdasarkan analisis data dan pembahasan yang telah dilakukan, dapat diambil kesimpulan sebagai berikut:

a. Tebal pelat berpengaruh pada lendutan untuk pembebanan sudut, semakin tebal pelat, lendutan yang terjadi semakin kecil. Hal ini karena semakin tebal pelat, kekakuan pelat semakin tinggi sehingga lendutan menjadi berkurang.

b. Pada pembebanan sudut, pengaruh koperan dalam mereduksi lendutan semakin turun dengan bertambahnya tebal pelat.

c. Penggunaan koperan dapat mereduksi lendutan pada pembebanan sudut sehingga dapat diperoleh tebal perkerasan yang lebih kecil, sebagaimana dalam hasil analisis dengan pelat tanpa koperan tebal $35 \mathrm{~cm}$ diperoleh lendutan maksimum sebesar 10,659 $\mathrm{mm}$ dan pelat tebal $25 \mathrm{~cm}$ dengan koperan diperoleh lendutan maksimum sebesar 10,413 $\mathrm{mm}$.

\section{REFERENSI}

Anonim, (1997). Jalan No. 038/TBM/1997, Tata Cara Perencanaan Geometrik Jalan Antar Kota. Departemen Pekerjaan Umum

Firdaus. W, 2010, Prediksi Perilaku Pelat Beton Di Atas Tanah Lunak Menggunakan Metode Boef (Beams On Elastic Foundation) Ditinjau Pada Variasi Tebal Pelat Beton Dan Nilai Pembebanan. Skripsi. Jurusan Teknik Sipil Universitas Sebelas Maret, Surakarta.

Hardiatmo, H.C. (2007). "Kajian Sebab-sebab Kerusakan Perkerasan Jalan di Ruas Jalan Demak-Kudus Terkait dengan Karakteristik Tanah Dasar (Subgrade)", Konferensi Nasional /Transportasi \& Geoteknik, Surakarta, Februari 2007, 116-120.

Hardiatmo, H.C. (2010). Metode Hitungan Lendutan, Momen dan Gaya Lintang Sistem Cakar Ayam Untuk Perancangan Perkerasan Jalan Beton, Dinamika Teknik Sipil, 10 (1), 27-33.

Hilyanto, R.R. (2013). Simulasi Perilaku Pelat Beton Sebagai Perkerasan Kaku Di Atas Tanah Subgrade dengan Menggunakan Metode Elemen Hingga. e-Jurnal Matriks Teknik Sipil, 1 (4), 424-431.

Islam, M. (2014). Using Of Finite Element In Developing A New Method For Rigid Pavement Analysis, International Journal of Civil Engineering And Technology (IJCIET), 5 (5), 6975.

Janco, R. (2010). "Solution Methods for Beam and Frames on Elastic Foundation Using the Finite Element Method", International Scientific Conference MSFE, Ostrava, Czech Republik, 13 September 2010.

Maske, N. A, Anandkumar, A \& Majumder, A. (2013). Analysis of rigid pavement stresses by Finite Element Method \& Westergaard's Method by varying sub-grade soil properties. International Journal of Engineering Science Invention, 2 (3).

Meshram, K. Goliya, H.S. \& Poddar, A. (2013). Stress Analysis and Determination of Effective k-value for Rigid Pavement. International Journal of Engineering Science and Technology, 5 (03), 468-474.

Puri, A. dkk, (2013). "Penerapan Metode Analisis Lendutan Pelat Terpaku Pada Model Skala Penuh dan Komparasi Dengan Uji Pembebanan". Konferensi Nasional Teknik Sipil 7 (KoNTekS 7), Surakarta, 24-26 Oktober 2013, G-201-G-211.

Suryawan, Ary, (2009). Perkerasan jalan Beton Semen Portland. Beta Offside. Yogjakarta 